\title{
Developing an Ecological Approach to the Strategic Implementation of UDL in Higher Education
}

\author{
Frederic Fovet ${ }^{1}$ \\ ${ }^{1}$ School of Education and Technology, Royal Roads University, Canada \\ Correspondence: Frederic Fovet, Associate Professor, School of Education and Technology, Royal Roads \\ University, 2005 Sooke Rd, Victoria, BC V9B 5Y2, Canada. E-mail: Frederic.fovet@royalroads.ca
}

Received: January 2, 2021 Accepted: May 15, 2021 Online Published: May 25, 2021

doi:10.5539/jel.v10n4p27 URL: https://doi.org/10.5539/jel.v10n4p27

\begin{abstract}
This paper argues that, as Canadian Higher Education campuses embark on large scale Universal Design for Learning (UDL) implementation, it is essential for them to take the time to strategically consider inherent institutional challenges before pushing ahead. As a result, it is argued that ecological theory will represent a unique and powerful lens in this process of implementation. The first section of the paper examines two inherent dangers being perpetuated in current UDL drives on the vast majority of Canadian campuses that have embarked on this adventure: (i) overreliance on disability service providers, and (ii) a conceptualization of UDL work in silos. The second half of the paper focuses on solutions, and on the idea of developing a strategic approach to UDL integration framed around ecological theory. The paper draws on an analysis of phenomenological data emerging from the author's own lived experience as a consultant responding regularly to the needs of post-secondary campuses with regards to the institutional adoption of UDL.
\end{abstract}

Keywords: universal design for learning, higher education, inclusion, learner diversity, accessibility services, teaching and learning, strategic planning, Ecological theory

\section{Context}

Universal Design for Learning (UDL) seeks to increase accessibility in the classroom and to offer diverse learners classroom experiences that have been proactively designed to be flexible and inclusive for all learners. UDL has grown increasingly popular within the Canadian Higher Education (HE) landscape over the last ten years while the student population on campuses has markedly become more diverse (Fovet, 2020). For several decades, however, UDL had been perceived as a mostly US framework, and as primarily focused on the K-12 sector (Meyer, Rose, \& Gordon, 2014), and this has created some tangible resistance among Canadian scholars and practitioners.

Things have changed progressively as a number of campuses across Canada have begun to see the relevance of UDL, amidst a rapid and dramatic explosion in the number of students seeking accommodations (Kumar \& Wideman, 2014; Capp, 2017). Even more recently, UDL has begun to show potential in assisting faculty create inclusive learning environments for international students (Fovet, 2019). The number of international students is indeed growing rapidly on all campuses as part of the decisive shift Canadian HE has taken towards internationalization (Glen \& Weinrib, 2011). These international students have specific needs and expectations with regards to teaching and learning and are not always currently being offered inclusive pedagogy that addresses these needs. UDL may help address this tension and support faculty within this landscape of internationalization. There is also evidence of emerging work with Indigenous students using UDL (James, 2018). There are, as a result, numerous communities of practice focusing on UDL that have flourished across Canadian universities, and faculty have begun the process of exploring how UDL can support them in redesigning courses and assessment for greater accessibility (Stewart, 2017).

Despite these encouraging developments, few campuses have succeeded in developing a strategic approach to campus wide implementation (Comfort \& North, 2014). UDL remains mostly an individual choice for instructors and departments, and literature has yet to emerge on how such efforts might be scaled up to a whole campus dimension. Management of change has not been appropriately explored in this respect; nor has the implementation of UDL been examined within the relative complexity of the HE organizational lens (Fovet, 2020). This paper argues it is time to explore the organizational hurdles which seem to thwart campus-wide UDL 
implementation in such scenarios. The paper also proposes a model which uses ecological theory to explore and evaluate strategic approaches to UDL promotion across campuses.

\section{Literature Review}

UDL in general terms positions itself as an innovative framework which shifts practitioners away from medical model practices and towards a social model approach (Gargiulo \& Metcalf, 2013). It indeed interprets disability not as an individual diagnostic label, but rather as an interaction between learners' individual embodiments and the specific design of learning environments (Levitt, 2017). In this sense, it can be argued that it translates the social model of disability into classroom practices (Fovet, 2014). The relevance of UDL in a HE context has been thoroughly examined by scholars (Gradel \& Edson, 2010; Rose, Harbour, Johnston, Daley, \& Abarbanell, 2006). The benefits of UDL implementation has by now in fact been evidenced well beyond issues of disability (Howard, 2004; Mole \& Fovet, 2013): international students and Indigenous students are shown within Canada to have just as much to gain from the rapid and systemic UDL implementation across HE campuses (Fovet, 2019; James, 2018). First generation students, life-long learners and culturally diverse learners also benefit from the use of UDL strategies in class (Boothe et al., 2018; Kieran \& Anderson, 2019). Once an instructor shifts away from a deficit model perspective, it becomes obvious to them that all diverse learners tend to experience fairly similar barriers in their access to learning in the post-secondary classroom. The issue is not the exceptionality of the learner; it is the design of the learning experience.

It would be unrealistic, however, to presume that UDL implementation occurs without challenges. The resistance of faculty, for instance, is also explored by scholars (Anstead, 2016). Even if the framework has triggered interest in the arena of student affairs well beyond accessibility (Houghton \& Fovet, 2012), instructors remain overall more cautious (Harrison, 2006; Moriña et al., 2020). Instructors indeed can fear that UDL will increase their workload; they at times mistakenly assume UDL implementation requires technological expertise; they can be affected by misperceptions that lead them to think UDL affects academic standards and integrity (Anstead, 2016). This leads to considerable obstacles when it comes to the task of scaling up UDL initiatives in HE.

There have, despite this, been encouraging individual initiatives led by faculty (Fidalgo \& Thormann, 2017), and a number of communities of practice have also shown promise (Salend \& Whittaker, 2018), but it is the issues of strategic implementation and development which fail to be tackled by the literature (Colorado State University, 2013). It remains unclear on most campuses which stakeholder should support the implementation of UDL and promote its roll out (Fovet, 2020). Accessibility services have usually led this momentum but they are inherently ambivalent about UDL and therefore probably not the most natural ally to lead this process of change (Fovet, 2018). There have also been attempts to promote UDL through teaching and learning units, or instructional designer departments, but outcomes have not been convincing from a strategic perspective (Davies et al., 2013; Singleton et al., 2019). This is in great part due to the fact that neither of these stakeholder groups really has much power to compel change on campuses; these units tend to have easy access to faculty who are already curious and interested in transforming pedagogy, but find it hard to reach instructors who are resistant to change. Academic freedom and hierarchical issues which are specific to HE make it impossible for pedagogical policy to be imposed on faculty (Woods et al., 2016). There has as a result been growing debate as to whether UDL implementation should occur 'top-down or bottom-up' and there are not definite solutions offered by the literature (Fovet, 2020).

The central issue is that UDL implementation is a process of change; this change is of large scope and is occurring in institutions which by their very nature are complex, multi-layered and vast. Mapping out, supporting and facilitating this process of change will be a challenging task requiring very specific skills. As it stands, however, UDL advocates have yet to explore, transfer, and use the solutions related to management of change that have already been thoroughly examined and applied in organizational psychology and management (Stouten, Rousseau, \& De Cremer, 2018). As a result, UDL implementation has thus far been simplistically framed as a mere process of pedagogical adjustment, requiring few resources and very little planning. In the end, UDL implementation across campuses is in fact a new and challenging process of management of change, and it is not currently being handled as such by HE institutions. This leads to strategic hiccups, and to an absence of convincing and tangible recorded outcomes that might otherwise serve as a blueprint for other interested campuses (Capp, 2017). We should by now have a body of literature which establishes best practices for the strategic organizational deployment of UDL as a framework, and instead there is only evidence of sporadic success. The danger here is that stakeholder and individuals on these campuses that might be demonstrating resistance to the adoption of UDL appear to be armed with arguments to push back further. This is currently hindering the development of UDL in the post-secondary sector (Al-Azawei, Serenelli, \& Lundqvist, 2016). 


\section{Methodological Reflection}

This paper approaches its themes and suggestions through the lens of phenomenology (Eddles-Hirsch, 2015). Phenomenology is a methodological framework which seeks to explore and analyze the lived experience of subjects who have expert understanding of a phenomenon; it seeks to grasp, showcase, and analyze the meaning making these individuals engage in when confronted with the phenomenon (Neubauer et al., 2019, Smith, 2019). Phenomenology has shown to be a popular and effective methodology within research on higher education (Webb \& Welsh, 2019). This study uses phenomenology to extract data from the author's lived experience as a UDL expert and consultant, having intimate experience of some HE institutions' initial experiences with UDL implementation. The author is currently faculty within an Education department but has also, in the past, been the manager of an accessibility centre on another large Canadian campus for a period of four years. He continues to act as a UDL consultant to colleges and universities in several provinces.

For the last five years, the author has therefore been involved in UDL implementation as a process in various ways: he has supported faculty engaged with this change in mindset, has offered large scale professional development exercises, and has collaborated with accessibility services, teaching and learning units and instructional designer departments; he has also offered recommendations to senior administration from an organizational perspective. He draws from these multiple roles and perspectives, and from this professional experience, to explain, describe, and analyze the current challenges most frequently faced by UDL advocates in HE. This professional perspective and phenomenological lens are again used when it comes to the formulation of the suggestions and recommendations which are offered in the last section of the paper with a view to successfully shifting the field in its approach to strategic UDL implementation. His subjective experience of the milieu and its complexity is central to the analysis offered here and the author embraces his own positioning within the topic area investigated.

The author has used processes of journaling (Annink, 2017), reviews of work notes and work products from his consultancy; he has examined his correspondence with the various stakeholders, and synthesized many of the experiences and perceptions he has had, as an integral actor in these processes, within each of the institutions he has supported with regards to UDL work; he also is part of several virtual chats on social media in which engages regularly (Frechette et al., 2020). He is uniquely positioned through his professional experience to have his finger on the pulse when it comes to the momentum around UDL in HE across Canada. This three-stage method of introspection, synthesis and recording of perception is a process he engages with richly and frequently, as UDL represents a central part of his research portfolio. The author uses a continuously reflective lens on his practice and assesses regularly core themes and categories that emerge within this capture of phenomenological. He has identified several codes in this process, but for the purpose of this study he is solely focusing on codes that relate specifically to organizational change, rather than pedagogical transformation. Two main codes were identified in this process, and these were used to sort and analyze the voluminous phenomenological data available; the two codes are used below in the analysis in order to structure the reflection and its presentation.

\section{Observations and Findings}

There are several important categories which emerge from the phenomenological data gathered by the author, but most of these relate to the pedagogical rethink and redesign which is encouraged by UDL in the classroom itself. These involve mostly instructors and students and do not represent the focus of this paper as UDL implementation in the classroom is an area already well researched. This paper seeks instead to address the gap which currently exists with regards to organizational considerations that arise in the campus-wide adoption of UDL. Two specific codes within the phenomenological data gathered by the author relate directly to strategic institutional implementation.

\subsection{The Ambivalent Role of Disability Service Providers}

Most UDL implementation efforts in Canadian HE have thus far been led by disability service providers (Bedrossian, 2018). While these units clearly are affected by the introduction of UDL and therefore appear as natural stakeholders, it may be naïve to assume that they have the resources or the motivation to successfully lead a systemic, cross-campus strategic roll out of UDL (Houghton \& Fovet, 2012). There are inherent contradictions in relying on accessibility services and this has already created substantial hurdles in UDL promotion. The future sustainable development of UDL will need to reconsider the assumption made about the roles of these units.

The commitment of accessibility units' commitment to UDL is often shaky due to the funding model within which they function (Harrison \& Wolforth, 2012). On most campuses the budget of these services is directly related to the number of students making service requests. If students are able to function independently on 
campus as a result of UDL implementation, this ironically often translates into a fall in the service requests and user demographics of the unit, and therefore a loss of revenue (Beck et al., 2014). There is talk in most provinces of reform of the funding model that supports services for students with disabilities in HE (OHRC, 2003), but at present the contradiction between the existing funding model and the aims of UDL are such that allocating UDL to accessibility services as an agenda in counter-productive and slows down implementation.

The funding model in disability service provision, more generally, also relies on a diagnostic approach (Kruse \& Oswal, 2018). Funds are linked directly to diagnostic categories. Documentation is required for the students to access services and for the units themselves to justify their budgetary needs, both at institutional and at provincial level (Dolmage, 2017). UDL promotion is incompatible with approaches that rely primarily on diagnostic disclosure and that reaffirm the medical model. UDL instead requires genuine adherence to a social model approach and this leads accessibility service to be extremely ambivalent in this area (Fovet, 2014). The social model frames disability, not as an inherent characteristic of the individual, but simply as an interaction and lack of fit between individual embodiments and the design of environments, products and services (Levitt, 2017). In the educational environment, the social model encourages educators to see disability as the result of a friction between the design of the learning experience - delivery and assessment - and the needs of diverse learners (Cigman, 2010). Learner diversity is seen as a given that must be proactively addressed in design; there is therefore no requirement for disclosure, diagnostic assessment, or supporting documentation (Al-Azawei et al., 2016).

More generally, the funding model within which accessibility services function also depends on learners' consistent reliance on student services. To justify their existence, productivity and efficiency, accessibility services require students to register early and remain constantly in contact with the unit (Mullins \& Preyde, 2013; Oswal, 2018). This is a powerful manifestation of the neoliberal model which now firmly frames the post-secondary sector and the business model values it imposes (Morgan, 2021). Indeed even the quality assurance and accountability measures of such units tend to assess solely the number of students consistently and regularly seeking support. This no longer represents the reality of the lived experience of students who may at times be encountering genuine inclusive UDL provisions in some of their courses and may not be consistently requiring services (Houghton \& Fovet, 2012). Once the UDL model becomes more widespread, a learner's reliance on disability services may be sporadic, or even minimal. Accessibility services will therefore eventually experience the spread of UDL as a direct threat to their development and their efficiency as documented in service request statistics. To some extent, the development of UDL is already perceived by accessibility staff as a challenge to their survival and the question 'Are we working ourselves out of a job?' is one that is frequently on the mind of accessibility services personnel, even if they are reticent to admit it.

Another obstacle that makes the commitment of accessibility units to UDL ambivalent and even fragile is the fact that beyond their funding model, they often conceive and design every part of their service delivery model from a medical model approach (Evans et al., 2017). A deep-rooted inherent adherence to a medical model approach shapes the format, tone and objectives of the 'intake' process, the flavour of the meetings themselves, the nature of the interventions, and the messaging with faculty. In almost every respect, the process to which a student must submit, from appointment making to the provision of accommodations, is clinical in nature, tone, and flavour. All these processes quickly become incompatible with UDL which must translate social model practices (Beck et al., 2014). This unquestioned adherence to the medical model is of course historical, but one should also look to the training and hiring of staff to understand this culture. Staff often have a background in "traditional" disability fields such as rehabilitation, occupational therapy, etc. There is usually a lack of pedagogical expertise with regards to the concept of inclusion, or even a lack of experience with Disability Studies, ironically; accessibility staff on some HE campuses may never have been exposed to the social model at all (Thornton \& Downs, 2010). UDL promotion is impossible in such a landscape and accessibility units will often as a result play mere lip service to it, rather than commit genuinely.

There are also complex issues around the very conceptualization of service provision in HE generally, when it comes to accessibility. The very service delivery model — in terms of interaction with the user — often contradicts notions of inclusive design. The intake, advising, communication and resources are sadly often not conceived through the lens of inclusive design, or with user experience (UX) in mind. They are, as a result, not genuinely accessible, in the sense that they create additional procedural barriers under the guise of providing accommodations (Kimball et al., 2016). A student with disabilities will for example often have to submit to innumerable processes and administrative hurdles that other students do not have to encounter; these administrative processes themselves are rarely accessible and inclusive in their format and design (Beck et al., 2014). Instead of focusing on UX, accessibility services are extremely service-centric. This also means that it 
becomes terribly easy for other campus partners to dismiss attempts by accessibility services to promote UDL across campuses when the advocates themselves adhere to administrative practices that contradict the very message they are putting forward (Houghton \& Fovet, 2012). 'Do as you preach, first' is often an easy come back from other stakeholders when these units launch initiatives, seek ownership, or seem to take the lead in the promotion of the UDL model across a campus.

Another common hurdle which occurs when accessibility services are made responsible for the promotion and development of UDL is their over-reliance on the notion of 'help'. The concept of help, though it may prima facie appear philanthropic and appealing, is a lens which construes the relationship to the student within an inherent set of power dynamics. The learner is seen as 'powerless', while the service provider purportedly possesses the solutions and controls the relationship (Mole \& Fovet, 2013). The individual-centered flavour developed by Rogers (Joseph, 2020), which has now been firmly embraced by counselling professions, has yet to leave its mark on the delivery format of accessibility services. This is a schema which locks the student in a passive role, one out of which they cannot grow without third party interventions; this passive role closely resembles the perceptions of the learner which are inherent to the 'banking model' and which are rejected by critical pedagogy (Benabe, 2010). UDL instead privileges the autonomy of the learner, and will attempt to reduce occasions when the student has to rely on others to obtain inclusive access to learning. This is a way of relating to the learner with disabilities which is still very foreign to accessibility services.

Another possible issue which comes to the forefront when the promotion of UDL is left to accessibility services is the fact that UDL these days relates to a much wider student population than just students with disabilities. Literature shows us how UDL benefits the inclusion of international students, as well as Indigenous students (Fovet, 2019; James, 2018). There is also growing evidence of the usefulness of UDL when it comes to creating inclusive provisions for first generation students, life-long learners, and culturally diverse students (Hromalik et al., 2020; Kieran, 2018). These are not service users that are routinely considered by accessibility services. In fact, the silo mentality that shapes service provision in HE means that accessibility services are ill-equipped to promote the use of UDL with other stakeholders or with regards to other groups of diverse learners. While a growing political momentum might be gained across campuses by demonstrating the relevance of UDL to a wide spectrum of diverse learners, accessibility services usually lack expertise or scope in formulating and showcasing this discourse. They are therefore usually unable to broaden the process of branding that must necessarily accompany UDL promotion across a campus when comes time to win over faculty and administrators.

Another reason for concern when UDL ownership is left in the hands of disability service providers is the fact that accessibility services are treated with a degree of caution by faculty members: this inherently limits the impact of any cross-campus UDL promotion they might attempt (Stevens et al., 2018). Few accessibility staff possess pedagogical expertise or training, and faculty will often feel that they are being guided on how to teach by staff who may not be in a position to advise them on pedagogy. This creates pushback and often hinders UDL promotion rather than advance it (Roth et al., 2018). It would also be naïve to not acknowledge the hierarchical barriers which exist between staff and faculty on HE campuses; institutional status often means that faculty will feel they can, to a great degree, disregard recommendations from accessibility services regarding UDL implementation, or inclusive pedagogy more generally (Lynch, 2017). These issues related to status and hierarchical barriers also affect communication channels, and accessibility services will often report that they are not in a position to engage faculty unless and instructor reaches out directly.

\subsection{Breaking Silo Mentality Around UDL in Higher Education}

There are other strategic hurdles which are plaguing current efforts to roll out UDL in systemic ways across campuses. They pertain to the very structure and historical development of student services and student affairs in HE. Silo mentality and territoriality between units represent two such hurdles that are heavily tangible in the current UDL landscape in HE (Lombardi \& Lalor, 2017).

First, stakeholders across campuses often have radically different backgrounds and theoretical stances (Thorp \& Goldstein, 2010). Universities and colleges are complex, multilayered institutions composed of staff that come from varied backgrounds, and it can become difficult to have these units and departments consider UDL from the same angle (Baker, Boland, \& Nowik, 2012). This strategic issue has not been that prevalent in UDL promotion in K-12 because schools are overall much more homogenous environments; HE institutions are not and it would be naïve to assume that the various parties and stakeholders will see eye to eye when it comes to UDL. This means that it is very difficult to get these units and departments to collaborate or to even discuss implementation in a cohesive way. The views of accessibility services, other student services staff, faculty, teaching and learning support, instructional designers, IT staff, and senior administrators on UDL will be diverse 
and often contradictory (Lombardi \& Murray, 2011). Getting these individuals and units to engage in a dialogue about implementation can at times seem like an insurmountable task.

HE generally, as a sector, is rife with silo mentality (Birx, 2019). Faculties do not even necessarily share expertise and resources. Student services and student affairs personnel rarely genuinely collaborate in an interdisciplinary way (O'Connor, 2012), and this leads to a fragmented view of UDL. HE campuses are diverse and often contradictory landscapes and any cohesive systemic change in mindset, when it comes to inclusive teaching and accessible pedagogy, will require first a reflection on how to bridge these divides, merge these cultures, and create interdisciplinary dialogue (Watson \& Watson, 2014). Something as simple as getting faculty, instructional designers and accessibility support staff around a table to proactively discuss change in pedagogy is a task which is rarely congenial to these professionals and is not yet part of institutional culture (Lombardi, Murray, \& Gerdes, 2011). UDL development suffers from this structural issue.

Far from collaborating, it is clear that often disability service providers, other student affairs units, and faculty end up struggling for dominance, instead of rallying to each other's causes and objectives. In a climate of increasing budgetary competitiveness, units and departments have adopted a survival mindset and are continuously - consciously or not - competing for budgetary priority (Cannizzo, 2018). This again means that UDL, though it should be a shared goal, is often discarded and dismissed by other units once it is seemingly adopted as a priority by one of them. To the issue of budgetary competitiveness, adds itself the issue of visibility and prestige. Ownership of a concept or initiative becomes crucial in this neo-liberal landscape (Morrish \& Sauntson, 2016), and sadly campus stakeholders are likely to push back against UDL development simply because it is being framed and showcased as another department's idea.

A more subtle challenge currently faced by UDL supporters in HE is the failure to connect the framework closely to the discourse on sustainable development. The sustainability movement in HE is in full transformation (Wals, 2007). Its advocates have realized that its relevance is not limited and that it no longer represents a minority voice within campus communities. Sustainability advocates and stakeholders have become able to verbalize, beyond operations management and energy policy, the organic links that connect sustainability to social justice (Glasser, 2007). Sustainability is now about governance and institutional values; it is about creating a future for HE institutions that appears not just economically viable, but also socially just, appealing to students, and meaningful within society as a whole; accessibility and UDL fit well within this lens. When UDL implementation, indeed, is presented as a change which requires initial investment but pays off in the long term by reducing later requirements for retrofitting, there is much more buy-in from instructors and administrators (Ralabate, 2011). The concept of sustainable teaching practice is one that creates significant interest and good will within this change process and UDL taps into this notion of sustainable, inclusive teaching. However, the change of mindset this implies has been slow to date. While sustainability would offer a perfect, cohesive, overarching and cementing theme for all the HE stakeholders who might be invested in the promotion of UDL, there is still much awareness that needs to be created in this area; a culture shift must first occur (Fovet, 2017).

A final strategic hurdle to UDL implementation, and another striking example of the silo mentality described in this section, is the insurmountable divide that seems, at times, to separate pedagogy from design thinking (Retna, 2016). Increasingly professionals are present on campuses that possess specific expertise and training in design and design thinking, and more specifically inclusive design. It is striking, however, how little this perspective has overlapped with views on pedagogy, or informed pedagogical choices. In a striking turn of irony, even campuses that now have inclusive design departments are failing to involve these units and professionals in the systemic UDL work that is being launched (IDRU, 2018). This reticence of campuses to embrace design thinking is hugely problematic when institutions are attempting to develop momentum around UDL, as the design stance and the acknowledgement of the importance of UX in HE, are central to this process.

\section{Recommendations}

There are currently two issues to tackle in the field of strategic UDL implementation in the post-secondary sector - beyond the issue of evidencing the pedagogical benefits of the mode to instructors. On the one hand, campuses require user-friendly and straightforward strategic models that can assist them with systemic cross-campus UDL implementation. On the other hand, campuses also require guidelines and tips, to guide them through this process of management of change, that fully recognize and acknowledge the multilayered complexity of the composition and modus operandi of HE institutions. Any blue print being presented to campuses for UDL development inherently runs the risk therefore of being overly simplistic and reductionist. Ironically, though the first message of UDL is that "one size does not fit all", implementers have thus far consistently attempted to offer unidimensional, and slightly hollow, organizational guidelines that take little 
notice of the huge disparities that exist among HE institutions, in terms of history, size, budgets, clientele, culture and organizational hierarchies (Roth, Pure, Rabinowitz, \& Kaufman-Scarborough, 2018).

The solution to this relative inertia and these frequent false starts, and to this lack of organizational reflection around systemic UDL implementation, is to adopt a strategic framework for reflection around the concept of roll-out that truly acknowledges the inherent complexity of the milieu. In this respect, ecological theory offers us a unique and rich lens through which UDL advocates are able to gauge the institutional environment, to identify factors of resistance and facilitators (Fovet, Jarrett, Mole, \& Syncox, 2014), and to develop a strategy that is congenial to the specific culture of the institution that is attempting to engage in this process. Bronfenbrenner's ecological model was originally grounded primarily within the fields of education and social work and focused on showing the impact of systems around individuals - either student or educator (Esolage, 2014; Hamwey et al., 2019; Kitchen et al., 2019). More recently, however, it has also been successfully used in Management and Organizational Psychology to interpret and showcase the way units and departments can themselves be subjected to complex and diverse systems that have an impact on their capacity to act and address challenge (Leech, Wiensczyk, \& Turner, 2009; Leonard, 2011).

A department which claims ownership over UDL implementation within a HE institution, will inherently find itself at the centre of a complex interaction of systems, as is illustrated in Figure 1. The wide array of variables listed in Figure 1 are drawn from the phenomenological analysis of the author's own experience with the process of UDL implementation in HE. This may not represent an exhaustive list of pertinent variables, but it offers a rich exploration of those that have most commonly come into play in Canadian HE initiatives with UDL of late. This representation is useful because it quickly brings to the forefront the fact that, when it comes to UDL, it is not necessarily the message itself that creates tension and challenges in this landscape, but that it may instead be the stakeholder in charge of supporting the message who faces inherent hurdles simply because of their pre-existing relationships with other campus units and parties.

In the process of change, the actor who takes on an agenda, creates momentum, and advocates for a shift in mindset is inherently navigating a political landscape where they must acknowledge their status, networks, alliances, and institutional history. This, in turn, will have an impact on its ability to lead the process of UDL implementation successfully. Adopting an ecological mapping of HE institutions will allow campuses to move away from a 'one size fits all' strategic approach to the UDL roll out (Stone et al., 2018; Lieberman, 2018). It will allow these institutions to develop a blue print that is unique to their setting, organic in nature, and reflects the specific complexity of their context. The use of ecological theory in UDL institutional implementation will also offer caveats against an over reliance on accessibility services, and allow institutions to proactively address the territoriality and silo mentality which would otherwise plague such efforts. The outcomes of this ecological reflection on implementation strategy will vary from institution to institution, and from context to context, but it is likely that the necessity of creating shared ownership - perhaps involving accessibility services, other student services units, teaching and learning departments, instructional designers, faculty and senior administration - will be readily apparent in many of these landscapes. A multidisciplinary and multi-stakeholder approach is likely to be readily appealing once institutions acknowledge the complexity of the process. 


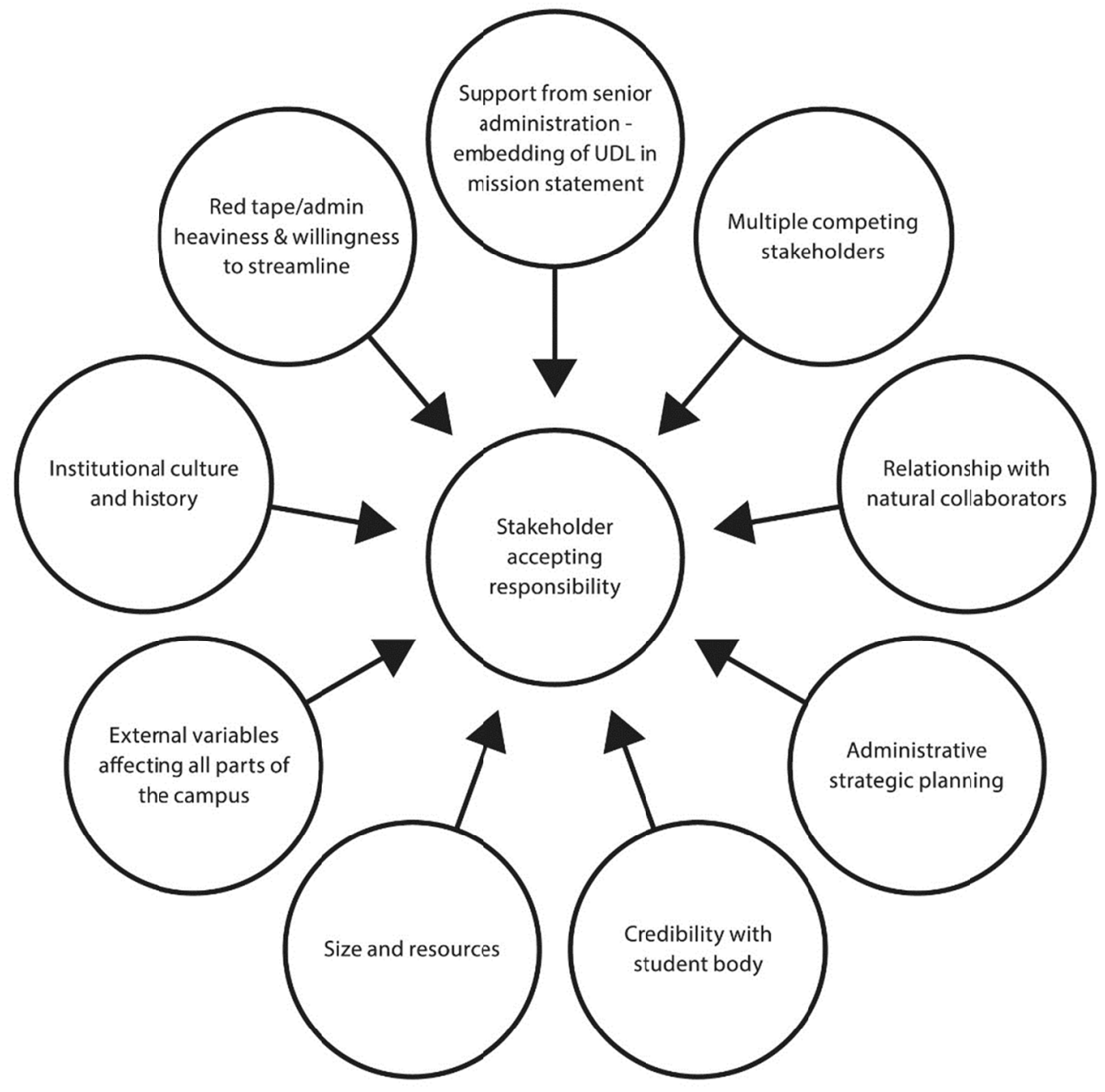

Figure 1. Ecological mapping around stakeholder 'ownership'

Source: Author.

\section{Conclusion}

This article has discussed how, within the drive for UDL implementation, the focus should not be solely on showcasing the pedagogical benefits of the model. Most of the scholarship to date has focused on convincing instructors of the urgency of adopting UDL to create inclusive provisions for all diverse learners. The analysis offered in this paper demonstrates that it is just as crucial and urgent to address the organizational and strategic challenges HE institutions might be facing when seeking to implement change and a shift in mindset with regards to inclusion. Specific hurdles have been identified in the current approach North American campuses have taken to UDL integration. One of the errors has notably been to make accessibility services responsible for the roll out. This inherently jeopardizes the process. Another error has been to ignore the silo mentality and the territoriality which exists between campus stakeholders. The neoliberal flavour of the post-secondary landscape inherently creates a climate of competitiveness and rivalry, more than one of collaboration. This again may hinder the process of UDL adoption when one-unit advocates for change, and other stakeholders can too easily 
adopt a position of resistance. The key outcome of the analysis presented in this article is that the use of ecological theory will be key when it comes to supporting campuses reflect on strategy, to designing an approach to implementation that is unique to their context, and to eroding factors of resistance that may in the end be more political and organizational than value-based.

\section{References}

Al-Azawei, A., Serenelli, F., \& Lundqvist, K. (2016). Universal design for learning (UDL): A content analysis of peer-reviewed journal papers from 2012 to 2015. Journal of the Scholarship of Teaching and Learning, 16(3), 39-56. https://doi.org/10.14434/josotl.v16i3.19295

Annink, A. (2017). Using the Research Journal during Qualitative Data Collection in a Cross-Cultural Context. Entrepreneurship Research Journal, 7(1). https://doi.org/10.1515/erj-2015-0063

Anstead, M. E. (2016). Teachers Perceptions of Barriers to Universal Design for Learning. PhD.Thesis, College of Education, Waldern Univerity. Retrieved from https://scholarworks.waldenu.edu/cgi/viewcontent.cgi?article=3002\&context=dissertations

Baker, K., Boland, K., \& Nowik, C. (2012). A campus survey of faculty and student perceptions of persons with disabilities. Journal of Postsecondary Education and Disability, 25(4), 309-329.

Beck, T., Diaz del Castillo, P., Fovet, F., Mole, H., \& Noga, B. (2014) Applying Universal Design to disability service provision: outcome analysis of a UD audit. Journal of Post-Secondary Education and Disability, 27(2), 209-222.

Bedrossian, L. (2018). Understand and promote use of Universal Design for Learning in higher education. Disability Compliance for Higher Education, 23, 7. https://doi.org/10.1002/dhe.30435

Benabe, L. (2010). Freire's Pedagogy of Freedom: Its Contribution to the Development of Ethical Teacher Professionality through the Implementation of the New Zealand Curriculum. Paideusis, 19(1), 5-15. https://doi.org/10.7202/1072319ar

Birx, D. L. (2019). Rethinking Higher Education: Integration as a Framework for Change. New Directions for Higher Education, 9-31. https://doi.org/10.1002/he.20309

Boothe, K., Lohmann, M., Donnell, K., \& Hall, D. (2018). Applying the Principles of Universal Design for Learning (UDL) in the College Classroom. The Journal of Special Education Apprenticeship, 7(3).

Cannizzo, F. (2018). Tactical evaluations: Everyday neoliberalism in academia. Journal of Sociology, 54(1), 77-91. https://doi.org/10.1177/1440783318759094

Capp, M. J. (2017). The effectiveness of universal design for learning: A meta-analysis of literature between 2013 and 2016. International Journal of Inclusive Education, 21(8), 791-807. https://doi.org/10.1080/13603116.2017.1325074

Cigman, R. (2010). Inclusion. In P. Peterson, E. Baker \& B. McGaw (Eds.), International Encyclopedia of Education (3ird ed., pp. 158-163). Amsterdam: Elsevier. https://doi.org/10.1016/B978-0-08-044894-7.00588-1

Colorado State University. (2013). Institutionalizing UDL: How to Implement UDL and Make It Sustainable! Retrieved from http://accessproject.colostate.edu/presentations/udl/consortium/june_08/workshop.php

Comfort, A., \& North, R. (2014). Full Speed Ahead: Developing a UDL Road Map for your Campus. Paper presented at The UDL Symposium, University of New Brunswick, November.

Davies, P. L., Schelly, C. L., Spooner, C. L., \& University, C. S. (2013). Measuring the effectiveness of universal design for learning intervention in postsecondary education. Journal of Postsecondary Education \& Disability, 26, 195-220.

Domalge, J. (2017). Academic Ableism. Disability and Higher Education. Ann Harbor, MI: University of Michigan Press. https://doi.org/10.3998/mpub.9708722

Eddles-Hirsch, K. (2015). Phenomenology and educational research. International Journal of Advanced Research, 3(8), 251-260.

Esolage, D. L. (2014). Ecological theory: Preventing youth bullying, aggression, and victimization. Theory into Practice, 53, 257-264. https://doi.org/10.1080/00405841.2014.947216

Evans, N., Broido, E., Brown, K., \& Wilke, A. (2017). Disability in Higher Education. A Social Justice Approach. San Francisco, CA: Jossey-Bass. 
Fidalgo, P., \& Thormann, J. (2017). Reaching Students in Online Courses Using Alternative Formats. The International Review of Research in Open and Distributed Learning, 18(2). https://doi.org/10.19173/irrodl.v18i2.2601

Fovet, F. (2014). Social model as catalyst for innovation in design and pedagogical change (pp. 135-139). Widening Participation through Curriculum Open University 2014 Conference Proceedings.

Fovet, F. (2017). Access, Universal Design and Sustainability of Teaching Practices: A Powerful Synchronicity of Concepts at a Crucial Conjuncture for Higher Education. Indonesian Journal of Disability Studies (IJDS), 4(2), 118-129. https://doi.org/10.21776/ub.IJDS.2017.004.02.4

Fovet, F. (2018). UDL_-Where the buck stops! In the change to a UDL Model, who does what? Opening plenary. Paper presented at the AHEAD 2018 Conference-Let's Bring the Elephant into the Room!- Reshaping the inclusive environment in further \& higher education, March.

Fovet, F. (2019). Not just about disability: Getting traction for UDL implementation with International Students. In N. Kate \& B. Sean (Eds.), Transforming Higher Education through Universal Design for Learning: An International Perspective Abingdon. Routledge. https://doi.org/10.4324/9781351132077-11

Fovet, F. (2020). Universal Design for Learning as a Tool for Inclusion in the Higher Education Classroom: Tips for the Next Decade of Implementation. Education Journal, 9(6), 163-172.

Fovet, F., Jarrett, T., Mole, H., \& Syncox, D. (2014). Like fire to water: Building bridging collaborations between Disability service providers and course instructors to create user friendly and resource efficient UDL implementation material. Collected Essays on Learning and Teaching, 7(1). https://doi.org/10.22329/celt.v7i1.3999

Frechette, J., Bitzas, V., Aubry, M., Kilpatrick, K., \& Lavoie-Tremblay, M. (2020). Capturing Lived Experience: Methodological Considerations for Interpretive Phenomenological Inquiry. International Journal of Qualitative Methods, 19. https://doi.org/10.1177/1609406920907254

Gargiulo, R. M., \& Metcalf, D. (2013). Teaching in Today's Inclusive Classrooms: A Universal Design for Learning Approach (2nd ed.). Belmont, CA: Wadsworth Cengage Learning.

Glasser, H. (2007). Minding the gap: the role of social learning in linking our stated desire for a more sustainable world to our everyday actions and policies. In A. E. J. Wals (Ed.), Social Learning towards a Sustainable World. Principles, Perspectives, and Praxis (pp. 35-62). Wageningen, The Netherlands: Wageningen Publishers.

Glen, J., \& Weinrib, J. (2011). Globalization and higher education in Canada. Handbook on Globalization and Higher Education, 222-240.

Gradel, K., \& Edson, A. J. (2010). Putting universal design for learning on the higher ed agenda. Journal of Educational Technology Systems, 38(2), 111-121. https://doi.org/10.2190/ET.38.2.d

Hamwey, M., Allen, L., Hay, M., \& Varpio, L. (2019). Bronfenbrenner's Bioecological Model of Human Development: Applications for Health Professions Education. Academic Medicine, 94(10), 1621. https://doi.org/10.1097/ACM.0000000000002822

Harrison, A., \& Wolforth, J. (2012). Findings from a Pan-Canadian survey of Disability Services Providers in Postsecondary Education. International Journal of Disability, Community \& Rehabilitation, 1(1).

Harrison, E. (2006). Working with Faculty Toward Universally Designed Instruction: The Process of Dynamic Course Design. Journal of Postsecondary Education and Disability, 19(2), 152-162.

Houghton, M., \& Fovet, F. (2012). Reframing Disability, reshaping the provision of services. Communiqué, $13(1), 16-19$.

Howard, K. L. (2004). Universal design for learning: Meeting the needs of all students. Learning and Leading with Technology, 31, 26-29.

Hromalik, C. D., Myhill, W. N., \& Carr, N. R. (2020). ALL Faculty Should Take this: A Universal Design for Learning Training for Community College Faculty. TechTrends, 64, 91-104. https://doi.org/10.1007/s11528-019-00439-6

IDRU. (2018). What do we mean by Inclusive Design? Retrieved from https://idrc.ocadu.ca/resources/idrc-online/49-articles-and-papers/443-whatisinclusivedesign

James, K. (2018). Universal Design for Learning (UDL) as a Structure for Culturally Responsive Practice. 
Northwest Journal of Teacher Education, 13(1), Article 4. https://doi.org/10.15760/nwjte.2018.13.1.4

Joseph, S. (2020). Why we need a more humanistic positive organizational scholarship: Carl Rogers' person-centered approach as a challenge to neoliberalism. Humanistic Psychologist, 48(3), 271-283. https://doi.org/10.1037/hum0000151

Kieran, L., \& Anderson, C. (2019). Connecting Universal Design for Learning with Culturally Responsive Teaching. Education and Urban Society, 51(9), 1202-1216. https://doi.org/10.1177/0013124518785012

Kimball, E. W., Wells, R. S., Ostiguy, B. J., Manly, C. A., \& Lauterbach, A. A. (2016). Students with disabilities in higher education: A review of the literature and an agenda for future research. In M. Paulsen (Ed.), Higher education: Handbook of theory and research (pp. 91-156). Berlin: Springer. https://doi.org/10.1007/978-3-319-26829-3_3

Kitchen, J. A., Hallett, R. E., Perez, R. J., \& Rivera, G. J. (2019). Advancing the Use of Ecological Systems Theory in College Student Research: The Ecological Systems Interview Tool. Journal of College Student Development, 60(4), 381-400. https://doi.org/10.1353/csd.2019.0043

Kruse, A., \& Oswal, S. (2018). Barriers to Higher Education for Students with Bipolar Disorder: A Critical Social Model Perspective. Social Inclusion, 6(4), 194-206. https://doi.org/10.17645/si.v6i4.1682

Kumar, K., \& Wideman, M. (2014). Accessible by design: Applying UDL principles in a first-year undergraduate course. Canadian Journal of Higher Education. The Canadian Journal of Higher Education, 44(1), 125-147. https://doi.org/10.47678/cjhe.v44i1.183704

Leech, S., Wiensczyk, A., \& Turner, J. (2009). Ecosystem management: A practitioners' guide. BC Journal of Ecosystems and Management, 10(2), 1-12.

Leonard, J. (2011). Using Bronfenbrenner's ecological theory to understand community partnerships: A historical case study of one urban high school. Urban Education, 46(5), 987-1010. https://doi.org/10.1177/0042085911400337

Levitt, J. (2017). Exploring how the social model of disability can be re-invigorated: in response to Mike Oliver. Disability \& Society, 32(4), 589-594. https://doi.org/10.1080/09687599.2017.1300390

Lieberman, M. (2018, February 7). Creating a 'Universal Design for Learning' Movement. Inside Higher Ed. Retrieved from https://www.insidehighered.com/digital-learning/article/2018/02/07/universal-design-learning-arrives-camp us-concerted-grassroots

Lombardi, A. R., \& Lalor, A. R. (2017). Faculty and administrator knowledge and attitudes regarding disability. In E. Kim \& K. C. Aquino (Eds.), Disability as diversity in higher education (pp. 107-121). New York, NY: Routledge. https://doi.org/10.4324/9781315644004-8

Lombardi, A. R., \& Murray, C. (2011). Measuring university faculty attitudes toward disability: Willingness to accommodate and adopt Universal Design principles. Journal of Vocational Rehabilitation, 34(1), 43-56. https://doi.org/10.3233/JVR-2010-0533

Lombardi, A. R., Murray, C., \& Gerdes, H. (2011). College faculty and inclusive instruction: Self-reported attitudes and actions pertaining to Universal Design. Journal of Diversity in Higher Education, 4(4), 250-261. https://doi.org/10.1037/a0024961

Lynch, R. J. (2017). Breaking the silence: A phenomenological exploration of secondary traumatic stress in U.S. college student affairs professionals. PhD. Thesis, Old Dominion University.

Meyer, A., Rose, D. H., \& Gordon, D. (2014). Universal Design for Learning: Theory and Practice. Wakefield, MA: CAST Professional.

Mole, H., \& Fovet, F. (2013a). 'You need me'-Examining the power and privilege dimension of service provision. Communiqué, 14(1), 31-33.

Mole, H., \& Fovet, F. (2013b). UDL — From disabilities office to mainstream class: How the tools of a minority are addressing the aspirations of the student body at large. Collected Essays on Learning and Teaching, 6, 121-126. https://doi.org/10.22329/celt.v6i0.3762

Morgan, H. (2021). Neoliberalism's influence on American universities: How the business model harms students and society. Policy Futures in Education. https://doi.org/10.1177/14782103211006655

Moriña, A., Perera, V. H., \& Carballo, R. (2020). Training Needs of Academics on Inclusive Education and 
Disability. SAGE Open. https://doi.org/10.1177/2158244020962758

Morrish, L., \& Sauntson, H. (2016). Performance Management and the Stifling of Academic Freedom and Knowledge Production. Journal of Historical Sociology, 29(1), 42-64. https://doi.org/10.1111/johs. 12122

Mullins, L., \& Preyde, M. (2013). The lived experience of students with an invisible disability at a Canadian university. Disability \& Society, 28(2), 147-160. https://doi.org/10.1080/09687599.2012.752127

Neubauer, B. E., Witkop, C. T., \& Varpio, L. (2019). How phenomenology can help us learn from the experiences of others. Perspectives on Medical Education, 8(2), 90-97. https://doi.org/10.1007/s40037-019-0509-2

O'Connor, J. (2012). Factors that Support or Inhibit Academic Affairs and Student Affairs from Working Collaboratively to Better Support Holistic Students' Experiences: A Phenomenological Study. EdD Thesis, Drexel University. Retrieved from https:/idea.library.drexel.edu/islandora/object/idea\%3A3988/datastream/OBJ/download/Factors_that_supp ort_or_inhibit_academic_affairs_and_student_affairs_from_working_collaboratively_to_better_support_ho listic_students experiences_a_phenomenological_study.pdf

Ontario Human Rights Commission. (2003). The opportunity to succeed: achieving barrier-free education for students with disabilities: Consultation report. Toronto, ON: OHRC.

Oswal, S. K. (2018). Can workplaces, classrooms, and pedagogies be disabling? Business and Professional Communication Quarterly, 81(1), 3-19. https://doi.org/10.1177/2329490618765434

Ralabate, P. K. (2011). Universal Design for Learning: Meeting the Needs of All Students. The ASHA Leader. https://doi.org/10.1044/leader.FTR2.16102011.14

Retna, K. (2016). Thinking about "design thinking": A study of teacher experiences. Asia Pacific Journal of Education, 36(sup1), 5-19. https://doi.org/10.1080/02188791.2015.1005049

Rose, D. H., Harbour, W. S., Johnston, C. S., Daley, S. G., \& Abarbanell, L. (2006). Universal design for learning in postsecondary education: Reflections on principles and their application. Journal of Postsecondary Education and Disability, 19(2), 17.

Roth, D., Pure, T., Rabinowitz, S., \& Kaufman-Scarborough, S. (2018). Disability Awareness, Training, and Empowerment: A New Paradigm for Raising Disability Awareness on a University Campus for Faculty, Staff, and Students. Social Inclusion, 6(4), 116-124. https://doi.org/10.17645/si.v6i4.1636

Salend, S., \& Whittaker, C. (2018). A Collaborative Process for Incorporating Universal Design for Learning and Evidence-Based Practice into Inclusive Teacher Education Programs. Oxford Research Encyclopedia of Education. https://doi.org/10.1093/acrefore/9780190264093.013.152

Singleton, K., Evmenova, A., Kinas Jerome, M., \& Clark, K. (2019). Integrating UDL strategies into the online course development process: Instructional designers' perspectives. Online Learning, 23(1), 206-235. https://doi.org/10.24059/olj.v23i1.1407

Smith, J. (2011). Evaluating the contribution of interpretative phenomenological analysis. Health Psychology Review, 5(1), 9-27. https://doi.org/10.1080/17437199.2010.510659

Stevens, C., Schneider, E., \& Bederman-Miller, P. (2018) Identifying faculty perceptions of awareness and preparedness relating to ADA compliance at a small private college in NE PA. American Journal of Business Education, 11(2). https://doi.org/10.19030/ajbe.v11i2.10142

Stewart, B. (2017). Practice What You Teach: UDL \& (aiming for) Communities of Practice in Adult Education. The Theory Blog. Retrieved from http://theory.cribchronicles.com/2017/05/24/practice-what-you-teach-udl-aiming-for-communities-of-practi ce-in-adult-education/

Stone, M. L., Kent, K. M., Roscoe, R. D., Corley, K. M., Allen, L. K., \& McNamara, D. S. (2018). The design implementation framework: Iterative design from the lab to the classroom. In R. D. Roscoe, S. D. Craig \& I. Douglas (Eds.), End-User Considerations in Educational Technology Design (pp. 76-98). Hershey, PA: IGI Global. https://doi.org/10.4018/978-1-5225-2639-1.ch004

Stouten, J., Rousseau, D., \& De Cremer, D. (2018). Successful organizational change: Integrating the Management practice and scholarly literatures. Academy of Management Annals, 12(2), 752-788. https://doi.org/10.5465/annals.2016.0095 
Thornton, M., \& Downs, S. (2010). Walking the Walk: Modeling Social Model and Universal Design in the Disabilities Office. Journal of Postsecondary Education and Disability, 23(1).

Thorp, H., \& Goldstein, B. (2010, August 10th). How to Create a Problem-Solving Institution. Chronicle of Higher Education. Retrieved from https://www.chronicle.com/article/How-to-Create-a/124153

Wals, A. E. J. (2007). Introduction. In A. E. J. Wals (Ed.), Social Learning towards a Sustainable World. Principles, Perspectives, and Praxis (pp. 17-32). Wageningen, The Netherlands: Wageningen Publishers. https://doi.org/10.3920/978-90-8686-594-9

Watson, W. R., \& Watson, S. L. (2014). Redesigning higher education: Embracing a new paradigm. Educational Technology, 54(3), 47-51.

Webb, A. S., \& Welsh, A. J. (2019). Phenomenology as a Methodology for Scholarship of Teaching and Learning Research. Teaching \& Learning Inquiry, 7(1), 168-181. https://doi.org/10.20343/teachlearninqu.7.1.11

Woods, T. M., Acosta, W. R., Chung, E. P., Cox, A. G., Garcia, G. A., Klucken, J. R., \& Chisholm-Burns, M. (2016). Academic Freedom Should Be Redefined: Point and Counterpoint. American Journal of Pharmaceutical Education, 80(9), 146. https://doi.org/10.5688/ajpe809146

\section{Copyrights}

Copyright for this article is retained by the author, with first publication rights granted to the journal.

This is an open-access article distributed under the terms and conditions of the Creative Commons Attribution license (http://creativecommons.org/licenses/by/4.0/). 